\title{
Genetically modified foods, science, consumers and the media
}

\author{
I. R. Rowland \\ Northern Ireland Centre for Diet and Health, School of Biomedical Sciences, University of Ulster, Coleraine BT52 1SA, UK
}

\begin{abstract}
In contrast to the situation in the USA, where a wide range of genetically modified (GM) foods is available, in Europe very few GM products have been approved for marketing as foods, and there is widespread public concern about their safety and environmental impact. The marketing of a GM crop for food use in Europe falls under the EC novel foods regulations, and applications require the submission of an extensive dossier of information. The safety evaluation of GM foods presents considerable problems both in the conduct and interpretation of experimental studies, because conventional toxicity tests used in the evaluation of simple chemicals may not be appropriate for whole foods. To rationalise the safety evaluation process and to circumvent the difficulties in toxicological assessment of food materials, the concept of substantial equivalence has been developed. The concept is that if it can be demonstrated that the novel food is essentially similar to its conventional counterpart in terms of critical nutritional or anutritional components, then it is likely to be no more or less toxic than the latter. The possible introduction of unintended effects by the genetic modification process is particularly problematic for the safety evaluation process. The new genomic and post-genomic techniques are potentially valuable in the safety evaluation of GM foods, although they are as yet in their infancy.
\end{abstract}

Genetic modification: Food safety evaluation

The subject of genetically modified (GM) foods in the UK is one that epitomises the gulf between science and the media, with the consumer trapped between the two. One of the problems is that, although there are important and valid concerns about environmental impact and consumer safety, the issue of GM foods has been caught up in other, more general, well-publicised worries about the power and influence of multinational industries, especially in chemical and biotechnology areas. There is also the issue of who benefits from the new technologies; clearly this group includes the biotechnology companies, who make a profit from selling the seed, and the farmers, who can benefit from improvements in agricultural practice. The advantages to the consumer are, at present, more nebulous, consequently a risk-benefit analysis is weighted heavily on the side of risk, however small that may be. There is an obvious need for the second-generation GM foods to provide direct and clear advantages for the consumer, either in the developed, or in the developing, world.

The present review will focus on the science of GM foods, and encompass a general background, a description of the GM-derived foods currently permitted on the UK market, a brief outline of the regulatory framework surrounding GM foods and a discussion of the main issues and problems surrounding the safety evaluation of GM foods.

\section{Conventional plant breeding $v$. genetically modified plants}

Genetic modification in the general sense (e.g. mutation, recombination) has occurred since the beginning of life on earth. In addition, man has genetically modified crops and animals by conventional means for thousands of years, with the aim of improving yield, enhancing disease resistance, altering (in some cases improving) taste, and maximising growth in adverse conditions such as drought and low temperatures. These modifications are normally brought about by extensive cross-breeding between the same or related species with different phenotypes. It is important to note that in some cases the initial stages of the selection process involve treatment of plants with powerful mutagens such as the alkylating agent N-methyl-N-nitro-N-nitrosoguanidine or doses of ionising radiation. Such treatment results in DNA damage and mutations in a wide range of genes, and requires a long (up to 10 years) and intensive 
process of breeding and selection to isolate plants with the required genotypic and phenotypic characteristics, and to eliminate unwanted or deleterious traits. For new crops bred using these conventional technologies there is no requirement for safety evaluation.

In contrast to these conventional breeding methods, modern molecular-biology techniques allow a gene that governs a specific trait to be identified, cloned and inserted into a plant. Genes from different species, genera or even kingdoms (e.g. animal to plant) can be transferred. Once transformed the plant is multiplied by conventional techniques. Clearly this procedure is more controlled and targeted than any conventional method. In theory, therefore, there are enormous advantages in the specificity of the initial genetic-modification process, and hence savings in time and cost in selecting out undesirable traits. However, concern has been raised about the potential of pleiotropic or unintended effects, for example, altered gene expression leading to increased levels of anti-nutrients, novel toxins or allergens, as a result of the insertion event. It is important to note, however, that conventional breeding methods allow similar opportunities for induction of unintended effects, due to genetic rearrangements or insertion of foreign genes into regulatory regions altering gene expression.

\section{Genetically modified foods available}

In the USA GM foods have been introduced into the market without the widespread media and public concern that has characterised the process in the UK. Consequently there is a large number and wide range of products available in the USA (Table 1). The USA also constitutes the greatest area of GM crops, which rose from about $2 \times 10^{6}$ ha in 1996 to $>20 \times 10^{6}$ ha in 1998 .

In contrast, in the UK only four types of GM-produced foods are currently permitted: rennet prepared from GM yeast (approved 1989; Ministry of Agriculture, Fisheries and Food (1989)), GM tomato paste (approved 1995; Ministry of Agriculture, Fisheries and Food (1994a)), herbicide-resistant soyabean (approved 1995; Ministry of Agriculture, Fisheries and Food (1994b)) and pest-resistant maize (approved 1996; Ministry of Agriculture, Fisheries and Food (1996a)).

The rennet derived from GM yeast provides an alternative to calf-stomach rennet that is acceptable to vegetarians. The chymosin gene was cloned and inserted into a yeast, which then produces the enzyme identical to that from calves.

Table 1. Examples of genetically modified foods available in the USA

\begin{tabular}{ll}
\hline Apples & Kiwi fruit \\
Asparagus & Lettuce \\
Barley & Maize \\
Beetroot & Melon \\
Rapeseed oil & Peanuts \\
Carrots & Potatoes \\
Cauliflower & Rice \\
Chicory & Soyabean \\
Cottonseed oil & Strawberries \\
Cucumber & Salmon \\
Grapes & Shrimp \\
\hline
\end{tabular}

The GM tomato paste is derived from a tomato in which the pectinase gene is switched off, thus delaying softening of the fruit, enabling it to be left to ripen on the vine longer and leading to improved taste.

Most controversy has surrounded Monsanto's GM soyabean (Monsanto Europe SA, Brussels, Belgium). This product comprised $40 \%$ of the global soyabean harvest in 1997. It contains a gene conferring resistance to the herbicide glyphosate (a broad spectrum weedkiller also produced by Monsanto) enabling the chemical to be applied to the soyabean crop at the optimal time for elimination of weeds, i.e. when the plants are in active growth. The advantages claimed include less herbicide use (reduced need for multiple applications of selective herbicides during the growing season), and better crop management, leading to higher yields.

A number of GM maize varieties with insect resistance have been approved in the UK (Ministry of Agriculture, Fisheries and Food, 1996a). The basis of the resistance is a gene derived from Bacillus thuringiensis subsp. Kurstaki which produces crystalline proteins, $\delta$-endotoxins, that when eaten by insects break down in the gut to core fragments with specific insecticidal activities. The $c r y l a(b)$ gene is recombinant form of the cryl gene in B. thuringiensis conferring resistance to a range of pests including: European corn borer (Ostrinia nubilalis); pink stem borer (Sesamia nonagrioides Lef.) southwestern corn borer (Diotraea grandiosella); fall armyworm (Spodoptera frugiperda); the corn earworm (Helicouerpa zea Boodie). Claimed advantages include reduced pesticide use, hence lower pesticide levels in food and less harm to the environment.

The insect-resistant maize provides a good example of the types of genetic modification introduced into GM crops (Ministry of Agriculture, Fisheries and Food, 1996a). The genes inserted comprise: two copies of cryla(b), a synthetic truncated form of the cryl gene in which only the coding sequence for the insecticidal protein has been copied; three regulator genes, phosphoenolpyruvate carboxylase promoter for expression in green tissue, Ca-dependent protein kinase promoter for expression in pollen and the cauliflower mosaic virus $35 \mathrm{~S}$ terminator sequence; the bar gene from Streptomyces hygroscopicus coding for glufosinate tolerance (plus cauliflower mosaic virus $35 \mathrm{~S}$ promoter and terminator for expression throughout plant) to facilitate selection of the GM plants; the bla gene from Escherichia coli (an antibiotic-resistance gene coding for an enzyme that inactivates ampicillin) used for selection of bacteria during development of the construct. The bla gene has bacterial regulatory sequences and is not therefore expressed in maize; in addition, the cytosine and guanine content is increased from 38 to $65 \%$ to increase expression in maize.

\section{Safety evaluation of genetically modified foods}

In the EU the marketing of a GM crop for use as a food falls under the 1997 EU Novel Foods Regulation no. 258/97/EC (European Union, 1997). Under this regulation, applications must be submitted to the competent authority of one EU country for evaluation. At the end of the $90 \mathrm{~d}$ period allowed 
for the evaluation, the European Commission sends the assessment plus a summary of the application to all Member States, who have $60 \mathrm{~d}$ to comment and raise objections. If there are objections, then the application is referred to the European Commission Standing Committee for Foodstuffs, which may consult the European Commission Scientific Committee for Food. If necessary a final decision is made by the Council of Ministers.

In 1997 the European Commission Scientific Committee on Food issued a set of recommendations for the safety assessment of novel foods, including GM foods (Commission of the European Communities, 1997). The Scientific Committee on Food suggested a decision-tree approach, which for the toxicological part may include a demand for separate animal studies. However, the Scientific Committee on Food does not give specific advice on how to do these studies, but states that the design should be determined on a case-by-case basis.

When a new GM food is submitted for approval under the novel foods regulations a substantial dossier of information is required (Commission of the European Communities, 1997), including the following:

specification of the novel food;

characterisation of the GM organism contained in the food product;

details of the methods used for the genetic modification, including the characterisation of the vector and its construction, in particular any parts of the vector that remain in the GM organism;

a description of the genes introduced, modified or deleted, including the marker genes, such as antibioticresistance genes, used in the selection process;

the specificity of the modification;

the rate, level and specificity of expression of the introduced genetic material;

the genetic stability of the modified organism;

toxicological assessment of the product (see below);

nutritional information;

anticipated intake and extent of use.

The safety evaluation of novel foods, including GM foods, presents considerable problems, both in the conduct and interpretation of experimental studies. Conventional toxicity tests that are used in the safety evaluation of novel chemical entities such as food additives, are often not applicable to foods. In the case of food additives these chemicals are usually well characterised in terms of chemical structure (often relatively simple) and mammalian metabolism. They can be administered in large quantities to animals over long periods and at high doses many times in excess of the anticipated human intake (which is usually quite low). These factors make it possible to define an exposure level at which no adverse effects are seen in animals which, by the application of appropriate safety factors, can be translated into an upper limit for human exposure. In contrast, novel foods are, by their nature, complex mixtures of complex chemicals, and problems of their bulk sets a limit on how much can be incorporated into diets for laboratory animals. Furthermore, incorporation of any foods, whether conventional or novel, at high levels into animal diets can disturb the nutrition of the animal, resulting in adverse effects that make it difficult to detect any effect of a specific GM-derived component. This factor, coupled with the relatively higher level of intake by human subjects, means that safety margins for intake cannot be determined.

The problems in testing foods, as opposed to chemicals, in standard toxicological tests are exemplified in the difficulties in interpreting experimental studies on irradiated foods, and more pertinently, the controversy surrounding the experiments with GM potatoes (Ewen \& Pusztai, 1999; Royal Society, 1999).

\section{Substantial equivalence}

In an attempt to rationalise the safety evaluation process and to circumvent the difficulties in toxicological assessment of food materials, the Organization for Economic Cooperation and Development (1993) developed the concept of substantial equivalence, which subsequently has been discussed and developed (World Health Organization, 1995). The concept is that if it can be demonstrated that the novel food is essentially similar to its conventional counterpart, then it is likely to be no more or less toxic than the latter. Hence, there is no need for extensive toxicological testing. It is widely applied by regulatory agencies throughout the world, including North America, Japan, Europe and Australia, in the safety assessment of novel foods.

Currently, the procedures for establishing substantial equivalence are:

1. identify critical nutritional or anutritional components of the food, e.g. fatty acid composition, vitamin content, carotenoid content. Identify known toxins (e.g. alkaloids in potatoes);

2. grow GM crop on several sites and for several years to establish variation due to geographical position, growth conditions, soil conditions and weather;

3. compare critical components in conventional and GM crops using appropriate statistical analysis.

If substantial equivalence of the GM food to a conventional food can be established, then no further safety assessment is required. However, a common outcome is that the GM food is substantially equivalent, except for a few clearly defined differences; for example, the presence of a Cryl protein in pest-resistant maize. In such cases, the safety implications of the differences need to be established (European Commission Scientific Committee on Food, 1997). In cases where the GM food is not substantially equivalent, where the differences are not defined, or where there is no non-GM counterpart, then extensive safety testing is required.

A major drawback to this substantial equivalence approach is stage 1, i.e. defining critical constituents of the plants to be used as comparators. It is possible that in the future a less-specific less-targeted approach can be used with the aid of genomic and post-genomic technologies, i.e. DNA microarrays, proteomics and metabolite profiling (see p. 28). 


\section{Allergenic potential}

Assessing the allergenic potential of novel foods presents major problems, since there are no reliable tests for predicting allergenicity. Consequently, a variety of approaches are taken in the safety evaluation process to provide an indication of allergenic potential (Fuchs \& Astwood, 1996; Metcalfe et al. 1996). For example, the stability of the novel protein(s) to the processing steps employed in the preparation of the food and to digestion processes are assessed, since many allergenic proteins are extremely resistant to degradation. The amino acid sequence of the novel protein can be compared with databases of known allergens. In addition, the reactivity of the introduced protein with immunoglobulin $\mathrm{E}$ from sera of individuals known to be allergic to the gene source can be assessed using ELISA or radioallergosorbent test assays. It is obviously advisable to avoid using plants containing known allergens, e.g. peanuts and brazil nuts, as sources of genes for GM plants.

\section{Unintended effects}

Much has been made in the media of the possibility of pleiotropic effects resulting from the insertion of genes into the GM plant. For example, the insertion of a gene coupled with a promoter into a plant chromosome could trigger the expression of a neighbouring gene for a toxin or allergen that was previously present but not expressed. It should be noted that pleiotropic effects could also occur during conventional plant breeding. Although unlikely, such unintended effects are possible, but are currently difficult to assess. However, new technologies may provide a solution (see below).

\section{Antibiotic resistance}

The use of antibiotics in the early stages of the process of genetic modification to select for the gene construct has led to concern that genes conferring resistance to antibiotics might be transferred to pathogenic gut bacteria, thus reducing the effectiveness of antimicrobial therapy. The likelihood of such horizontal transfer of DNA from food to gut bacteria is small, and the antimicrobial resistance marker usually used is kanamycin, an antibiotic that is not used clinically and has limited veterinary use. However, in some GM plants resistance to ampicillin, a more widely used antibiotic, is used as a marker. The Advisory Committee on Novel Foods and Processes (Ministry of Agriculture, Fisheries and Food, 1996b) in the UK and a recent FAO/WHO expert consultation report (Food and Agriculture Organization, 2000) both advocate that the antibiotic marker genes should be excised after the initial multiplication step in bacteria, and should not be present in the plant grown for food use.

\section{Future approaches to safety evaluation: genomic and post-genomic technologies}

As mentioned earlier, a major difficulty in the substantial equivalence approach in the safety assessment of a GM food is defining the critical constituents of the plants to be used for the comparisons with the conventional plant. Clearly, this process relies on previous knowledge and/or assumptions as to which constituent to choose. The new and exciting developments in genomic and post-genomic technologies of DNA microarrays, proteomics and metabolic profiling offer great potential for the safety evaluation process (Kuiper et al. 2000; Noteborn et al. 2000; van Hal et al. 2000). Using these techniques, it is theoretically possible to compare metabolic profiles of GM and conventional plants and to identify differences and similarities in thousands of genes and proteins in the two types of plants, thus providing a less-specific and less-targeted approach to substantial equivalence. The methods also offer the possibility of identifying unintended effects of genetic manipulation, which is a common criticism of current evaluation procedures. These approaches are currently the subject of a number of European collaborative projects (e.g. SAFOTEST and ENTRANSFOOD), and present an exciting opportunity to provide an integrated view of the response of a plant cell to genetic manipulation at the level of transcription, translation and metabolism.

Clearly, however, these new techniques are in their infancy, although they are developing extremely rapidly. Before applying them in the safety evaluation process, there are difficulties to be overcome in terms of standardisation and validation of the assays, how to apply statistics to the enormous database of information that can be accrued by these methods and, not least, how to interpret the data obtained and incorporate it into the safety evaluation process.

\section{Future developments in genetically modified foods}

Adverse media publicity and public concern are inhibiting the marketing of new GM foods in Europe, and very few new applications for GM foods are reaching the EU for evaluation for food use. Nevertheless, there are a large number of 'second-generation' GM foods at various stages of development. Many of these foods are targeted on benefits for farming. For example, crops are being developed with viral resistance (to cucumber mosaic virus in cucumber, tomato, pepper and to rice yellow mottle virus), insect resistance (Colorado beetle (Leptinotarsa decemlineata), vine weevil (Otiorhynchus sulcatus), codling moth (Cydia pomonella) in fruit trees), nematode resistance, frost tolerance (gene from arctic fish transferred to tomato, potato, strawberry) and salt or heavy metal tolerance. However, some GM foods with specific benefits for consumers are being developed; for example, 'Golden' rice, a strain with high $\beta$-carotene content of potential use in developing countries to combat vitamin A deficiency (Ye et al. 2000; Potrykus, 2001). Recently, Muir et al. (2001) reported the transformation of tomato with a gene for chalcone isomerase from Petunia, resulting in a 78 -fold increase in flavonol content in the peel of the fruit. Interestingly, the press coverage (Henderson, 2001) was favourable, suggesting that if GM foods are shown to have potential benefits for consumers, the usual antagonism of the media may be mitigated. 


\section{References}

Commission of the European Communities (1997) Commission recommendation of 29 July 1997 concerning the scientific aspects and the presentation of information necessary to support applications for the placing on the market of novel foods and novel food ingredients and the preparation of initial assessment reports under Regulation (EC) No. 258/97 of the European Parliament and of the Council. C(97) 2634 final. Official Journal of the European Communities 40, L253/1-45.

European Commission Scientific Committee on Food (1997) Opinions on the Assessment of Novel Foods Expressed 7 June 1996, 12/13 December 1996. Reports of the Scientific Committee on Food, 40th series, European Commission DGIII/5915/97. Brussels: Commission of the European Communities.

European Union (1997) European Union Regulation (EC) no. 258/97 of the European Parliament and of the Council of 27 January 1997 concerning novel foods and novel food ingredients. Official Journal of the European Communities L43.

Ewen SWB \& Pusztai A (1999) Effect of diets containing genetically modified potatoes expressing Galanthus nivalis lectin on rat small intestine. Lancet 354, 1353-1354.

Food and Agricultural Organization (2000) Report of a Joint FAO/WHO Expert Consultation On Foods Derived From Biotechnology. Rome: FAO.

Fuchs RL \& Astwood JD (1996) Allergenicity assessment of foods derived from genetically modified plants. Food Technology 50, 83-88.

Henderson M (2001) GM tomato 'reduces risk of disease'. Times 1 May issue, available at http://www.thetimes.co.uk/article/ $0,, 2.122472,00 . h t m l$

Kuiper HA, Kok EJ \& Noteborn HPJM (2000) Profiling techniques to identify differences between foods derived from biotechnology and their counterparts. Report of a Joint FAO/WHO Expert Consultation on Foods Derived from Biotechnology, pp. 2-12. Rome: FAO.

Metcalfe DD, Astwood JD, Townsend R, Sampson HA, Taylor SL \& Fuchs RL (1996) Assessment of the allergic potential of foods derived from genetically engineered crop plants. Critical Reviews in Food Science and Nutrition 38, S165-S186.

Ministry of Agriculture, Fisheries and Food (1989) Advisory Committee on Novel Foods and Processes Annual Report 1989, p. 6. London: MAFF Publications.
Ministry of Agriculture, Fisheries and Food (1994a) Advisory Committee on Novel Foods and Processes Annual Report 1994, p. 3. London: MAFF Publications.

Ministry of Agriculture, Fisheries and Food (1994b) Advisory Committee on Novel Foods and Processes Annual Report 1994, p. 6. London: MAFF Publications.

Ministry of Agriculture, Fisheries and Food (1996a) Advisory Committee on Novel Foods and Processes Annual Report 1996, p. 17. London: MAFF Publications.

Ministry of Agriculture, Fisheries and Food (1996b) The Use of Antibiotic Resistance Markers in Genetically Modified Plants for Human Food. Clarification of Principles for Decision-making. London: MAFF Publications.

Muir S, Collins GJ, Robinson S, Hughes S, Bovy A, de Vos CHR, van Tunen AJ \& Verhhoeyen ME (2001) Overexpression of petunia chalcone isomerase in tomato results in fruit containing increased levels of flavonols. Nature Biotechnology 19, 470-474.

Noteborn HPJM, Lommen A, Van der Jagt RCM \& Weseman JM (2000) Chemical fingerprinting for the safety evaluation of unintended metabolic changes in transgenic food crops. Journal of Biotechnology 77, 103-114.

Organization for Economic Cooperation and Development (1993) Safety Evaluation of Foods Derived by Modern Technology: Concepts and Principles. Paris: OECD.

Potrykus I (2001) Golden rice and beyond. Plant Physiology 125, $1157-1161$.

Royal Society (1999) Review of data on possible toxicity of GM potatoes. Statement 9/99 pp. 1-4, available at http://www. royalsoc.ac.uk/files/statfiles/document.29.pdf

van Hal NLW, Vorst O, van Houwelingen AMML, Kok EJ, Peijnenburg A, Aharoni A, van Tunen AJ \& Keijer J (2000) The application of DNA microarrays in gene expression analysis. Journal of Biotechnology 78, 271-280.

World Health Organization (1995) Application of the Principle of Substantial Equivalence to the Safety Evaluation of Foods or Food Components from Plants Derived by Modern Biotechnology. Geneva: WHO Food Safety Unit.

Ye XD, Al-Babili S, Kloti A, Zhang J, Lucca P, Beyer P \& Potrykus I (2000) Engineering the provitamin A (beta-carotene) biosynthetic pathway into (carotenoid-free) rice endosperm. Science 287, 303-305. 